\title{
Current guidelines for high-density lipoprotein cholesterol in therapy and future directions
}

This article was published in the following Dove Press journal:

Vascular Health and Risk Management

8 April 2014

Number of times this article has been viewed

\author{
Bishnu H Subedi ${ }^{1,2}$ \\ Parag H Joshi' \\ Steven R Jones' \\ Seth S Martin' \\ Michael J Blaha' \\ Erin D Michos' \\ 'Johns Hopkins Ciccarone Center \\ for the Prevention of Heart Disease, \\ ${ }^{2}$ Greater Baltimore Medical Center, \\ Baltimore, MD, USA
}

\begin{abstract}
Many studies have suggested that a significant risk factor for atherosclerotic cardiovascular disease (ASCVD) is low high-density lipoprotein cholesterol (HDL-C). Therefore, increasing HDL-C with therapeutic agents has been considered an attractive strategy. In the prestatin era, fibrates and niacin monotherapy, which cause modest increases in HDL-C, reduced ASCVD events. Since their introduction, statins have become the cornerstone of lipoprotein therapy, the benefits of which are primarily attributed to decrease in low-density lipoprotein cholesterol. Findings from several randomized trials involving niacin or cholesteryl ester transfer protein inhibitors have challenged the concept that a quantitative elevation of plasma HDL-C will uniformly translate into ASCVD benefits. Consequently, the HDL, or more correctly, HDL-C hypothesis has become more controversial. There are no clear guidelines thus far for targeting HDL-C or HDL due to lack of solid outcomes data for HDL specific therapies. HDL-C levels are only one marker of HDL out of its several structural or functional properties. Novel approaches are ongoing in developing and assessing agents that closely mimic the structure of natural HDL or replicate its various functions, for example, reverse cholesterol transport, vasodilation, anti-inflammation, or inhibition of platelet aggregation. Potential new approaches like HDL infusions, delipidated HDL, liver X receptor agonists, Apo A-I upregulators, Apo A mimetics, and gene therapy are in early phase trials. This review will outline current therapies and describe future directions for HDL therapeutics.
\end{abstract}

Keywords: high-density lipoprotein, lipids, cholesterol, atherosclerosis, cardiovascular disease, therapy

\section{Introduction}

Atherosclerotic cardiovascular disease (ASCVD) is a major cause of mortality globally. Epidemiological studies have clearly shown low high-density lipoprotein cholesterol (HDL-C) and high low-density lipoprotein cholesterol (LDL-C) as ASCVD risk factors. ${ }^{1}$ However, despite substantial risk reductions conferred by targeting LDL-C reduction with statin therapy, significant risk remains as demonstrated by incident and repeated ASCVD events that still occur despite treatment with statins. ${ }^{2}$ Hence, there has been a continual search for potential therapies in order to further reduce ASCVD mortality and morbidity by elevating HDL-C levels and/or enriching HDL functions.

HDL particles are accountable for reverse cholesterol transport (RCT), a process which can facilitate reversal of atheroma formation. Despite this, findings from several randomized trials have challenged the concept that a quantitative elevation of plasma HDL-C will uniformly translate into ASCVD benefits. ${ }^{3}$ The ongoing excitement over HDL treatment and its future directions is mostly based on the studies assessing the
Correspondence: Erin D Michos Division of Cardiology Johns Hopkins Hospital 600 N. Wolfe Street, Carnegie 568 Baltimore, MD 21287, USA

Tel: +I 4105026813

Email edonnell@jhmi.edu
Dovepress

http://dx.doi.org// $0.2147 /$ VHRM.S45648
Vascular Health and Risk Management 2014:10 205-2/6

(c) (i) (\$) $\odot 214$ Subedi et al. This work is published by Dove Medical Press Limited, and licensed under Creative Commons Atribution - Non Commercial (unported, v3.0) 
association of HDL functionality and ASCVD risk. Modification of HDL has been heavily researched, particularly in recent years. This review will outline current therapies and describe future directions for HDL therapeutics.

\section{Epidemiology of HDL}

One of the major risks for cardiovascular deaths is low HDL-C. There is angiographic correlation between coronary artery disease (CAD) and reduced HDL-C. Framingham was the first large study identifying HDL-C as a protective factor against ASCVD. Observational data show that each $1 \mathrm{mg} / \mathrm{dL}$ rise in HDL-C is associated with a drop in CAD by $2 \%-3 \%{ }^{4}$ Having more than $60 \mathrm{mg} / \mathrm{dL}$ of HDL-C is an independent negative risk factor; however, low HDL-C may not sufficiently predict ASCVD if LDL-C is low. ${ }^{5}$ Mendelian randomization data does not uphold HDL-C as causative factor; ${ }^{6}$ however, this does not rule out the causality for other metrics of HDL structure and functions.

Findings from recent studies have increased controversy surrounding the HDL hypothesis ${ }^{7}$ due to several reasons: 1) lack of evidence showing a direct causal role of HDL-C to outcomes through a primary biological mechanism (thus far, the data have been linked to the specific drugs used, which usually have complex relationships between HDL-C and other lipid parameters); 2) complex HDL metabolism, which is unlike the apolipoprotein (Apo) B-containing lipoproteins that generally exhibit dosedependent risk; 3) multiple mechanisms of action of HDL outside of RCT and lipid transport; 4) inability of HDL-C to accurately reflect RCT flux and effect on outcomes; and 5) cross-sectional nature of most epidemiology studies of
HDL-C, not reflective of longitudinal or interventional effects with drugs.

The total concentration of HDL-C levels in the serum is only one aspect of HDL out of its several structural or functional properties (for example, RCT, anti-inflammatory, antioxidant, or anticoagulant activities). Some patients with ASCVD may still have dysfunctional HDL in spite of normal or even high HDL-C. ${ }^{8}$ Types of diet, exercise, drugs, or concomitant diseases also influence HDL-C levels. The association of the structure of the HDL particle with its functionality and metabolism has not been fully clarified. More research will be indispensable to evaluate the association of HDL functionality with ASCVD risk. Based on current understanding and given strong epidemiological and biological evidence, targeting HDL still remains a potentially promising way to further reduce ASCVD risk. ${ }^{9}$

\section{The quality and functions of HDL versus the quantity of HDL-C}

The HDL lipoprotein is the densest and smallest lipoprotein particle in circulation. The life cycle of HDL is summarized in Figure 1 and its functions in Table 1. For historical reasons, cost considerations, and other technical and practical challenges related to other measures of HDL, the most common method of laboratory assessment is HDL-C: the aggregate cholesterol concentration associated with HDL particles.

Different lifestyle and therapeutic approaches have shown a quantitative elevation of static HDL measures at various degrees (Table 2). While several static measures of HDL lipidation (HDL-C) and structure (ApoA-I) correlate with clinical and epidemiologic risk data, it is essential to emphasize that

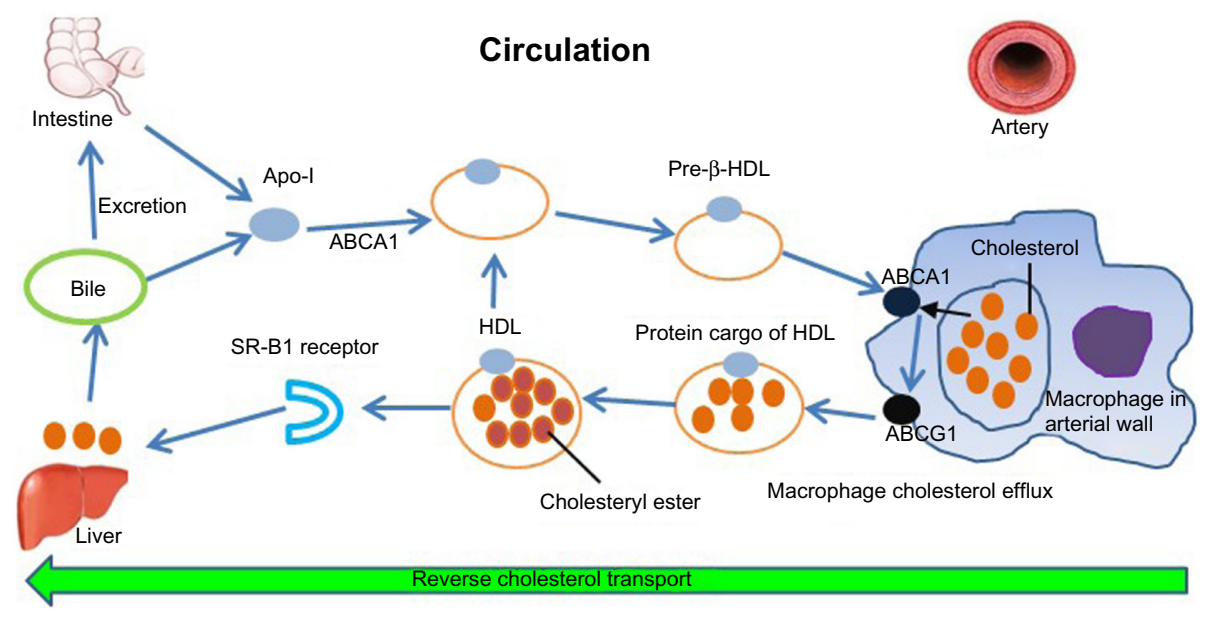

Figure I Life cycle of HDL.

Adapted by permission from Macmillan Publishers Ltd: Nature Medicine, ${ }^{83} \Subset 2012$.

Abbreviations: ABCA, ATP-binding cassette transporter family A; ABCG, ATP-binding cassette transporter family G; Apo, apolipoprotein; HDL, high-density lipoprotein; SR-BI, scavenger receptor class BI. 
Table I Functions of HDL

\begin{tabular}{|c|c|}
\hline $\begin{array}{l}\text { Reverse cholesterol } \\
\text { transport }\end{array}$ & $\begin{array}{l}\text { Promotes net movement of cholesterol to the } \\
\text { liver from peripheral tissues via plasma }\end{array}$ \\
\hline Role in & Inhibits endothelial cell adhesion molecules \\
\hline inflammation ${ }^{4,7}$ & $\begin{array}{l}\text { Inhibits inflammatory cytokines, infiltration of } \\
\text { leukocytes and free radical species in arterial wall } \\
\text { Exhibits potential proinflammatory role as acute } \\
\text { phase reactant }\end{array}$ \\
\hline Antioxidant effects ${ }^{4,7}$ & $\begin{array}{l}\text { Inhibits oxidized LDL production through } \\
\text { several mechanisms }\end{array}$ \\
\hline Antithrombotic & Inhibits platelet activation and aggregation \\
\hline effects $^{7}$ & $\begin{array}{l}\text { Inhibits thrombin-mediated production of } \\
\text { tissue-factor in vascular endothelial cells } \\
\text { Inhibits factor } X \\
\text { Enhances activities of protein } S \text { and protein } C\end{array}$ \\
\hline \multirow[t]{2}{*}{ Antiapoptotic effects ${ }^{7}$} & $\begin{array}{l}\text { Prevents oxidized LDL-prompted apoptosis by } \\
\text { impeding intracellular signaling }\end{array}$ \\
\hline & $\begin{array}{l}\text { Promotes TNF } \alpha \text { - generated apoptosis and } \\
\text { apoptosis stimulated by growth factor deficit }\end{array}$ \\
\hline Vasodilation ${ }^{7}$ & Stimulates production of nitric oxide \\
\hline
\end{tabular}

Abbreviations: HDL, high-density lipoprotein; LDL, low-density lipoprotein; TNF, tumor necrosis factor.

these are crude measures and do not directly reflect the quality and function of HDL, including RCT efficiency, inflammation, redox conditions, or the proteomic cargo of HDL. Furthermore, whether increasing the cholesterol concentration within HDL particles leads to improvement in atherosclerosis is debatable. Many recent niacin trials with modest elevation in HDL-C or cholesteryl ester transfer protein (CETP) inhibitor trials with remarkable elevations in HDL-C have failed to produce any significant improvement in clinical outcomes.

Therefore, in recent years, the focus has shifted to develop agents that closely mimic the structure of HDL or improve the endogenous production of HDL particles, which are expected to have similar effects to natural HDL. ${ }^{10}$ Many of these studies are in early phases.

\section{Current guidelines for HDL in therapy}

Whereas statin treatment to lower LDL-C and risk is consistently the primary target of dyslipidemia therapy across

Table 2 Percent of HDL-C elevation anticipated by therapy

\begin{tabular}{ll}
\hline Smoking cessation & $5 \%$ \\
Weight reduction & $5 \%-20 \%$ \\
Physical exercise & $5 \%-30 \%$ \\
Statins & $5 \%-10 \%$ \\
Fibrates & $5 \%-15 \%$ \\
Niacin & $15 \%-30 \%$ \\
CETP inhibitors & $30 \%-138 \%$ \\
ApoA infusions & $60 \%-70 \%$
\end{tabular}

Abbreviations: Apo, apolipoprotein; CETP, cholesteryl ester transfer protein: HDL-C, high-density lipoprotein cholesterol. the US, European, and Canadian guidelines, there is less consensus on targeting HDL-C. Prior lipid guidelines from the Adult Treatment Panel (ATP)-III had been widely followed in dyslipidemia treatment. ${ }^{11}$ ATP-III stated that after LDL-C targets were satisfied, lowering non-HDL-C (at least $\leq 30 \mathrm{mg} / \mathrm{dL}$ greater than the LDL-C goal) could be a secondary goal.

The idea of targeting HDL-C is generally avoided though desirable levels are often specified. For example, the American Association of Clinical Endocrinologist's Guidelines recommend raising HDL-C as much as possible but minimally to $>40 \mathrm{mg} / \mathrm{dL}$ in both women and men with isolated low HDL-C and strong risk factors (presence of CAD, CAD equivalents, or 10-year risk $>20 \%$ ) (Grade C, best evidence level 4). ${ }^{12}$

The latest European Society of Cardiology guidelines (2011) consider niacin as the most efficient drug to raise HDL-C (class IIa). ${ }^{13}$ However neither the results of Atherothrombosis Intervention in Metabolic Syndrome with low HDL-C/High Triglyceride and Impact on Global Health Outcomes (AIMHIGH $)^{14}$ nor Heart Protection Study 2: Treatment of HDL to reduce the incidence of vascular events (HPS2-THRIVE) ${ }^{15}$ trials were available when this guideline was released. Canadian guidelines recommend consideration for lipid-lowering therapy in subjects if their risk defined by a total cholesterol/HDL-C ratio is $>6.0$ (class IIb) but have no specific endorsements for targeting HDL-C or HDL. ${ }^{16}$

More recently, the 2013 American College of Cardiology and American Heart Association cholesterol guidelines contain substantial changes from ATP-III and other existing guidelines. ${ }^{17}$ The expert panel made no recommendations for specific LDL-C or non-HDL-C targets for the primary and secondary prevention of ASCVD because of lack of evidence from randomized, controlled, clinical trials to support treatment to specific targets. Instead, the new guidelines identified four groups of primary and secondary prevention patients in whom physicians should focus their efforts to reduce ASCVD events. Primary targets are appropriate "intensity" of statin therapy in order to achieve relative reductions in LDL-C. Nonstatin drugs have no clearly defined roles, and their use is left to the judgment of clinicians. No specific recommendation was made for targeting HDL-C in therapy due to lack of convincing data. ${ }^{17}$

\section{Established drug therapies Statins}

Statin therapy generally increases HDL-C by $5 \%-10 \%$; however, most risk reduction is achieved by lowering LDL-C. ${ }^{18}$ 
HDL-C can predict residual risk for ASCVD events among patients sufficiently treated with statins. ${ }^{5}$ Some studies indicate that among patients adequately treated with statins who have low HDL-C, the ApoB/ApoA-I ratio may better predict a first acute major coronary event. ${ }^{19}$

Significant risk remains despite adequately addressing LDL-C and ApoB on statins. Though much residual risk is related to nonlipid factors, the hope is that some of this risk could be attenuated by HDL-targeted therapies. Therefore, several agents are currently in development.

\section{Fibrates}

Fibrates can raise HDL-C up to $15 \%$ by enhancing the expressions of ApoA-I and ApoA-II. These also reduce triglycerides (TG) and modestly lower LDL-C. Fibrates reduce fibrinogen levels and increase fibrinolysis. Unfortunately, most studies investigating the outcome of fibrates on ASCVD and allcause mortality have produced discouraging findings. ${ }^{20}$

However, in a subgroup analysis of the ACCORD trial, diabetic and metabolic syndrome patients with both higher baseline TG ( $\geq 204 \mathrm{mg} / \mathrm{dL})$ and lower HDL-C ( $\leq 34 \mathrm{mg} / \mathrm{dL})$ did benefit from fenofibrate in addition to simvastatin. ${ }^{21}$ This was particularly true in men. Among dyslipidemic patients, TG levels decreased and HDL-C increased, along with a relative risk reduction of $10 \%$ for major cardiovascular events $(P=0.048)$ and $13 \%$ for coronary events $(P<0.0001)$. This effect was absent in patients without atherogenic dyslipidemia. ${ }^{21}$ These findings are similar to post hoc subgroup analyses performed from the previous fibrate monotherapy trials, the Bezafibrate Infarction Prevention studies $^{22}$ and the Helsinki Heart Study. ${ }^{23}$

\section{Niacin}

Niacin can considerably increase HDL-C, up to $30 \%$. It also decreases LDL-C, suggesting a possible mechanism for benefits seen in prestatin niacin trials. In the poststatin era, in patient populations with aggressively treated LDL-C (ApoB) levels, there was no improvement when niacin was added. ${ }^{24}$ It has not been tested in statin-treated patients with residually elevated LDL-C or ApoB. A summary of clinical trials of niacin is presented in Table 3.

The AIM-HIGH trial failed to demonstrate any advantage for niacin when combined with statin therapy compared to statin alone. ${ }^{14}$ A nonsignificant trend toward greater risk of ischemic stroke was noted. The HPS-2/THRIVE trial showed more adverse events with no benefits. ${ }^{15}$ Participants in HPS-2/THRIVE also had very tightly controlled LDL-C levels at baseline. It is unknown to what extent the adverse events were related to niacin or the flushing inhibitor that was administered along with niacin (laropiprant).

Furthermore, in a recent study by Khera et al, long-acting niacin added to statin therapy increased HDL-C but did not enhance measures of functionality such as RCT or the antiinflammatory index. ${ }^{25}$ Thus, the clinically relevant action of

Table 3 Summary of niacin trials

\begin{tabular}{|c|c|c|}
\hline Drugs & Trials & Outcomes \\
\hline Niacin alone & Coronary Drug Prevention project $(1975)^{68}$ & Reduced $\mathrm{Ml}$ and stroke in 3,906 patients with prior $\mathrm{MI}$. \\
\hline $\begin{array}{l}\text { Add on colestipol } \\
\text { versus placebo }\end{array}$ & $\begin{array}{l}\text { Cholesterol Lowering Atherosclerosis } \\
\text { study (CLAS) }(1987)^{69}\end{array}$ & $\begin{array}{l}\text { Significant atherosclerosis regression was noted in treatment group } \\
\text { compared to placebo. Fewer people were found to develop new } \\
\text { lesions in grafts and coronary arteries. }\end{array}$ \\
\hline Add on statin & $\begin{array}{l}\text { HDL Atherosclerosis Treatment } \\
\text { study (HATS) }(2001)^{70}\end{array}$ & $\begin{array}{l}\text { Simvastatin plus niacin showed notable angiographic and clinical } \\
\text { benefits among patients with CAD and low HDL-C levels. }\end{array}$ \\
\hline Add on statin & $\begin{array}{l}\text { Arterial Biology for the Investigation of the } \\
\text { Treatment Effects of Reducing Cholesterol } \\
\text { (ARBITER) } 2(2004)^{71}\end{array}$ & $\begin{array}{l}\text { ERN added to statins slowed the progress of atherosclerotic disease } \\
\text { among patients with previous CAD and moderately-low HDL-C. }\end{array}$ \\
\hline Add on statin & ARBITER $3(2006)^{72}$ & $\begin{array}{l}\text { When added to statins, ERN significantly increased HDL-C and } \\
\text { regression of CIMT. }\end{array}$ \\
\hline Add on statin & $\begin{array}{l}\text { ARBITER-6 HDL and LDL Treatment } \\
\text { Strategies (HALTS) }(2010)^{73}\end{array}$ & $\begin{array}{l}\text { Niacin showed superiority to ezetimibe for regression of CIMT } \\
\text { among patients on statins. }\end{array}$ \\
\hline Add on statin & $\begin{array}{l}\text { Atherothrombosis Intervention in Metabolic } \\
\text { Syndrome with low HDL-C/High Triglyceride } \\
\text { and Impact on Global Health Outcomes } \\
\left(\text { AIM-HIGH) }(201 \mathrm{II})^{14}\right.\end{array}$ & $\begin{array}{l}\text { This trial was ended early as it did not show increased benefit on } \\
\text { ASCVD outcomes, in spite of a } 10 \% \text { increment in HDL-C. }\end{array}$ \\
\hline $\begin{array}{l}\text { Add on statin; } \\
\text { niacin/laropiprant }\end{array}$ & $\begin{array}{l}\text { Heart Protection Study 2: Treatment of HDL } \\
\text { to reduce the incidence of vascular events } \\
\text { (HPS2-THRIVE) }(2013)^{15}\end{array}$ & $\begin{array}{l}\text { No reduction in CVD events compared to statins alone over a mean } \\
\text { follow-up of } 3 \text { years. }\end{array}$ \\
\hline
\end{tabular}

Abbreviations: ASCVD, atherosclerotic cardiovascular disease; CAD, coronary artery disease; CIMT, carotid artery intima-media thickness; CVD, cardiovascular disease; ERN, extended-release niacin; HDL-C, high-density lipoprotein cholesterol; MI, myocardial infarction. 
niacin may actually be lowering of atherogenic lipid fractions rather than producing favorable changes in the beneficial properties of the HDL.

Niacin may still have a role in dyslipidemia treatment. In recent niacin trials, all patients were already treated with statins. Because of the further LDL-C lowering effect, niacin may be suitable for those individuals who cannot tolerate maximal statin treatment or those who cannot achieve the desired LDL-C/Non-HDL-C/ApoB goal on a maximal statin treatment. ${ }^{26}$

Another approach is to treat with ARI-3037MO, a oncea-day structural analog of niacin, presently in Phase I trials. ${ }^{27}$ Future investigators must be aware that conducting "surrogate-endpoints" trials versus "events-driven" trials for niacin may be challenging. ${ }^{28}$

\section{Future therapeutic options}

Several agents targeting HDL function (Figure 2) are being evaluated in various phases of development. Most of the currently available agents are summarized in Table 4 .

\section{Cholesteryl ester transfer protein inhibitors}

Cholesteryl ester transfer protein (CETP) promotes the transport of cholesteryl esters to proatherogenic ApoB-containing lipoproteins (intermediate density lipoprotein, LDL, very low-density lipoprotein [VLDL] and its remnants) from antiatherogenic HDLs, and it exchanges TGs from VLDLs or LDLs to HDLs at the same time. Reduced CETP activity is coupled with increased HDL-C and diminished LDL-C, a combination that is probably antiatherogenic. ${ }^{29}$

A pivotal regulator of the RCT pathway is CETP, which generally has an inverse relationship with cardiovascular protection, although data are mixed. ${ }^{30}$ Several approaches have been followed to counteract CETP functions, including antisense deoxynucleotides, small molecule inhibitors of CETP, and vaccination. ${ }^{7}$ Four CETP inhibitors have been tested in clinical trials so far, with disappointing results in the first two trials, and trials involving anacetrapib and evacetrapib are ongoing (Table 5). ${ }^{30}$

\section{Recombinant HDL infusions}

Instead of indirectly raising HDL-C by intervening in HDL metabolism, there is interest in raising HDL directly by infusing recombinant or reconstituted HDL (rHDL) into blood. ApoA-I Milano, perhaps the most well-known rHDL, is a variant of apolipoproteins, originally discovered in a small percentage of the population in rural Milan. In spite of extremely minimal HDL-C, carriers surprisingly exhibited marked longevity and reduced risk for atherosclerosis due to a mutation in ApoA-I, causing dimerization of ApoA-I molecules in HDL, increased effectiveness in RCT, and resistance to HDL catabolism. ${ }^{31}$

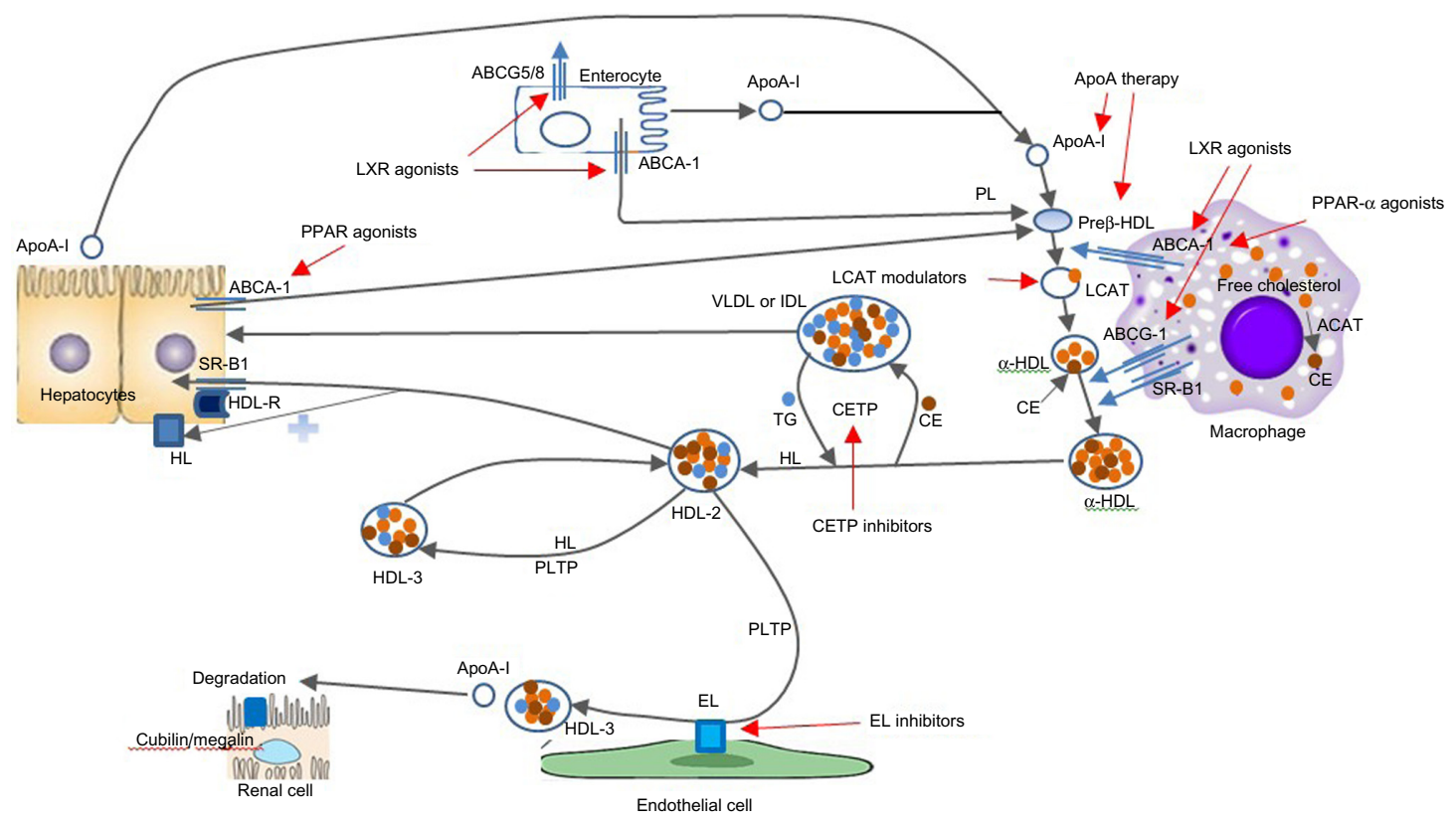

Figure 2 Therapeutic targets for HDL therapy (adapted by permission from Macmillan Publishers Ltd: Nature Reviews Cardiology, ${ }^{40} \odot 20 \mathrm{I}$ ).

Abbreviations: ABCA, ATP-binding cassette transporter family A; ABCG, ATP-binding cassette transporter family G; ACAT, acyl-CoA cholesterol acyltransferase; Apo, apolipoprotein; CE, cholesteryl esters; CETP, cholesterol ester transfer protein; EL, endothelial lipase; HDL, high-density lipoprotein; HL, hepatic lipase; IDL, intermediate density lipoprotein; LCAT, lecithin cholesterol acyl transferase; LXR, liver X receptor; PL, phospholipid; PLTP, phospholipid transfer protein; PPAR, peroxisome proliferatoractivated receptor; R, receptor; SR-BI, scavenger receptor class BI; TG, triglycerides; VLDL, very low-density lipoprotein. 
Table 4 List of potential drugs targeting HDL therapeutics

\begin{tabular}{|c|c|c|}
\hline Class of drugs & Mechanism of action & Drug names \\
\hline Recombinant ApoA-I Milano & Augment ApoA-I/HDL reservoir directly & ETC-216 \\
\hline Purified native ApoA-I/ & Augment ApoA-I/HDL reservoir directly & CSL-III \\
\hline phospholipids & & CSL-II2 \\
\hline ApoA-I upregulators & Augment ApoA-I/HDL reservoir directly & $\mathrm{RVX}-208$ \\
\hline ApoA-I mimetic & $\begin{array}{l}\text { Mimic ApoA functionality, facilitate lipidation of ApoA-I at } \\
A B C A I \text {, and formation of nascent discoidal } H D L \text { particles }\end{array}$ & L-4F, D-4F, 6F, 5A, ATI-526I, ETC-642 \\
\hline Delipidated HDL & Augment ApoA-I and HDL reservoir directly & Selective delipidated HDL \\
\hline Gene therapy & Modulate HDL levels and cholesterol efflux & miR-33 \\
\hline LXR agonists & Enhance RCT and macrophage cholesterol efflux & $\begin{array}{l}\text { LXR } \alpha / \beta, \text { LXR-623 } \\
\text { T0901317, GW3965, ATI-III }\end{array}$ \\
\hline Niacin receptor agonists & Strengthen ApoA-I and HDL reservoir indirectly & ARI-3037MO \\
\hline FXR receptor & Alter HDL levels & FxR-450 \\
\hline CETP inhibitors & $\begin{array}{l}\text { Augment ApoA-1/HDL pool, increase lipid content } \\
\text { and size of alpha HSL particles }\end{array}$ & Anacetrapib MK-0859, evacetrapib LY248595 \\
\hline EL inhibitors & Increase HDL-C & $\begin{array}{l}\text { Boronic acid inhibitors, } \\
\text { selective sulfonylfuran urea }\end{array}$ \\
\hline LCAT activators & Enhance RCT & rLCAT \\
\hline PPAR agonists & Enhance transcription of $\mathrm{ABCAI}$ & $\begin{array}{l}\text { LY518674, CP-778 875, CP-90069I, GW5015 I6, } \\
\text { GW0742, tesaglitazar, muraglitazar, aleglitazar, pioglitazone }\end{array}$ \\
\hline $\begin{array}{l}\text { Omega- } 3 \text { polyunsaturated } \\
\text { fatty acids and esters }\end{array}$ & $\begin{array}{l}\text { Increase HDL2-cholesterol, particularly in women; } \\
\text { act in large part through reduction in triglycerides }\end{array}$ & DHA, EPA, and respective esters \\
\hline
\end{tabular}

Table 5 CETP inhibitor trials

\begin{tabular}{lll}
\hline Drugs & Trials & Outcomes \\
\hline Torcetrapib & $\begin{array}{l}\text { Investigation of Lipid Level Management to Understand } \\
\text { its Impact in Atherosclerotic Events (ILLUMINATE) trial } \\
(2007)^{74}\end{array}$ & $\begin{array}{l}\text { Increased mortality, possibly from off-target effects on blood pressure } \\
\text { and electrolytes. }\end{array}$
\end{tabular}

Rating Atherosclerotic Disease Change by Imaging With

A New CETP Inhibitor(RADIANCE) (2007) $)^{75}$

Investigation of Lipid Level Management Using Coronary

Ultrasound to Assess Reduction of Atherosclerosis

by CETP Inhibition and HDL Elevation (ILLUSTRATE) $(2007)^{76}$

Dalcetrapib Efficacy and safety of dalcetrapib in patients with recent acute coronary syndrome (dal-OUTCOMES) $(2012)^{77}$ Safety and efficacy of dalcetrapib on atherosclerotic disease using novel non-invasive multimodality imaging (Dal-PLAQUE) Phase Ilb $(20 \mathrm{II})^{78}$

Anacetrapib Determining the EFficacy and Tolerability of CETP INhibition with AnacEtrapib (DEFINE) (2010 ${ }^{79}$

Randomized EValuation of the Effects of Anacetrapib Through Lipid-modification (REVEAL) (ongoing) ${ }^{80}$

Evacetrapib A randomized trial $(2011)^{81}$

Assessment of Clinical Effects of Cholesteryl Ester Transfer Protein Inhibition With Evacetrapib in Patients at a High-Risk for Vascular Outcomes (ACCELERATE) study (ongoing) ${ }^{82}$
Elevated HDL-C and lowered LDL-C substantially; also increased systolic BP and did not change CIMT.

Reduced LDL-C and enhanced HDL-C markedly. Study group had elevated BP. There was no significant decrease in evolution of coronary atheroma.

Increased HDL-C up to $40 \%$, without altering LDL-C, with no improvement on CVD outcomes.

Increased HDL-C by $31 \%$ with decreased CETP over a mean of 2 years. Failed to show plaque progression at 2 years or inflammatory response at 6 months. No increased adverse events noted.

Improved HDL-C by $138 \%$, decreased LDL-C by $40 \%$, and decreased Lp(a) by $36 \%$.

No significant variation in BP compared with placebo noted.

Will test effects of anacetrapib $100 \mathrm{mg}$ daily added to atorvastatin in reducing $\mathrm{CHD}$ events among 30,000 individuals with ASCVD or diabetes. To be completed in 2017.

Evacetrapib alone or combined with statins reduced LDL-C (14\%$36 \%)$ and augmented HDL-C (54\%-129\%). No discernible effects on BP or production of aldosterone or cortisol were noted.

To test the effects on ASCVD events among II,000 postacute coronary syndrome patients.

Abbreviations: ASCVD, atherosclerotic cardiovascular disease; BP, blood pressure; CETP, cholesteryl ester transfer protein; CHD, coronary heart disease; CIMT, carotid artery intima-media thickness; CVD, cardiovascular disease; HDL-C, high-density lipoprotein cholesterol; LDL-C, low-density lipoprotein cholesterol; LP(a), lipoprotein a. 
After recombinant ApoA-I Milano showed safety in both in vitro and in vivo testing in animals, Nissen et al in 2003 reported that a recombinant ApoA-I Milano-phospholipid complex, named ETC-216, could produce a significant regression of atherosclerosis in coronary arteries as measured by intravascular ultrasound among 47 post-acute coronary syndrome (ACS) patients. ${ }^{32}$ Another study in 2006 presented similar results. ${ }^{33}$ A recent study showed rHDL(Milano) has better plaque stabilizing and anti-inflammatory activities than wild-type HDL. ${ }^{34}$

CSL-111 is an rHDL compound containing ApoA-I derived from phosphatidylcholine and human plasma. The first human trial of CSL-111 studied 183 ACS patients. Monthly infusions of CSL-111 (40 mg/kg) were well tolerated; however, the higher dose $(80 \mathrm{mg} / \mathrm{kg})$ regimen was withdrawn due to elevated liver enzymes. ${ }^{35}$ Nonsignificant difference in the atheroma size was observed between CSL-111 and placebo groups, however, significant improvement was seen in coronary score and plaque characterization index. ${ }^{35}$

Subsequently, another trial has examined the impact of CSL-111 on vascular function (a surrogate cardiovascular disease [ASCVD] marker) among 29 ACS patients allocated to $80 \mathrm{mg} / \mathrm{kg}$ infusion of CSL-111 versus albumin. Though this rHDL augmented HDL-C by $64 \%$ and lessened LDL-C by $23 \%$, it did not improve vascular function. ${ }^{36}$ Besides these, other rHDLs named ECT-216 and CSL-112 (reformulated CSL-111) are being studied in early phase trials. ${ }^{37} \mathrm{MDCO}-$ 216, a renamed ApoA-I Milano, is also expected to enter clinical studies. ${ }^{38}$

Despite these promising results, further studies of ApoA-I Milano and rHDLs have not moved forward as expected, probably because these complex proteins are expensive to produce and must be given intravenously, with no oral formulation currently available.

\section{Delipidated HDL infusions}

Autologous infusion of delipidated HDL is another method to increase plasma HDL by selectively removing ApoA-I HDL particles and reinfusing cholesterol-depleted functional pre- $\beta$ HDL. ${ }^{39}$ Lipid Sciences Plasma Delipidation System-2 (Lipid Sciences, Inc., Pleasanton, CA, USA) is one pharmacotherapeutic approach, which forms pre $\beta$-like HDL from $\alpha H D L$ using an apheresis technique to extract cholesterol from plasma HDL. ${ }^{40}$

The first human trial of autologous delipidated HDL infusions versus placebo with 28 ACS patients showed a nonsignificant decrease in atheroma size $(P=0.27) .{ }^{41}$ From a safety standpoint, no hepatotoxicity or hypersensitivity reactions were noted; however, one third of patients experienced hypotension from HDL apheresis. ${ }^{41}$ This was a small pilot study to assess safety and feasibility. It remains to be seen whether such regression of atheroma burden will translate into reduced clinical ASCVD outcomes.

\section{HDL mimetics}

HDL mimetics are shorter amphipathic-peptides that do not contain exact ApoA-I sequences but mimic ApoA-I functions. Compound 18A (with 18 amino acids), the earliest ApoA-I mimetic peptide, failed to reduce atherosclerosis in animals despite having many structural similarities to Apo-I. ${ }^{7}$ Subsequently, improved peptides were developed (by increasing number of phenylalanine residues $[\mathrm{F}]$ ) labeled $2 \mathrm{~F}$ through $7 \mathrm{~F}^{42}$

Among the initial few mimetics, only 4F showed efficacy for inhibiting the in vitro production of LDL-induced membrane cofactor protein, a regulator of complement pathways and inflammation. ${ }^{7}$ It has shown reasonable potential when tested in animals prompting Phase I/II human trials in highrisk ASCVD patients. ${ }^{43}$

The use of D-amino acids makes the amphipathic peptides resistant to gut proteases, hence deliverable as an oral therapy. L-amino acid equivalents need to be administered parenterally to avoid degradation in the gut. Oral administration of D-4F significantly decreased proinflammatory HDL despite low blood peptide levels. ${ }^{44}$ The impacts of subcutaneous D-4F and L-4F on atheromatous lesions were similar when tested in cholesterol fed rabbits. ${ }^{7}$ Oral D-4F can cause HDL remodeling that can influence plasma lecithin-cholesterol acyltransferase (LCAT) activity and promote cholesteryl ester transport onto nascent HDL at ATP-binding cassette transporter family A (ABCA)1, thus activating the RCT pathway. ${ }^{45}$ With higher doses, D-4F displays detergent-like activities that can independently remove cholesterol from cells. Furthermore, the efficiency of these mimetics can be increased by adding end-blocking groups (acetyl and amine) to stabilize the class A amphipathic helix. ${ }^{46}$

New mimetic peptides have been produced that do not necessitate supplemental chemical groups for effectiveness. Peptide 6F showed anti-inflammatory properties in animals, offering a new option to oral ApoA-I mimetics. ${ }^{7}$ Preclinical studies have shown that both $5 \mathrm{~F}$ and $6 \mathrm{~F}$ but not $7 \mathrm{~F}$ could suppress membrane cofactor protein-1 production in vitro human cells. ${ }^{47}$

$5 \mathrm{~A}$ peptide is a mimetic that can effectively reduce the expression of adhesion molecules (vascular cell adhesion 
molecule-1 and intercellular adhesion molecule-1). ${ }^{7}$ It also facilitates cholesteryl ester transport onto discoidal HDL when bound (via ApoA-I) to ABCA1. ${ }^{48}$ ETC-642 showed similar anti-inflammatory properties compared to rHDL in rabbits. ${ }^{49}$ ATI-5261 is another synthetic mimetic, which exerts its effects through ABCA1, boosts efflux of cholesterol from peripheral cells, and also augments fecal cholesterol transport. ${ }^{50}$ This agent currently awaits clinical studies in humans. $^{7}$

These mimetic agents are interesting, but they are still many years away from having clinical outcome data available.

\section{Peroxisome proliferator-activated receptors agonists}

Peroxisome proliferator-activated receptors (PPARs) are a group of nuclear receptor proteins that have important roles in the metabolism of glucose and lipids. Common subtypes are alpha, gamma, and delta. These receptors enhance ABCA1 transcription that facilitates cholesterol efflux into nascent HDL from cells. All PPAR agonists rely on the liver $\mathrm{X}$ receptors (LXR) and PPAR- $\alpha$ promoter activity to execute their functions. ${ }^{3}$ Drugs like fibrates, thiazolidinediones, and glitazars have affinity for these receptors, producing changes in HDL metabolism. ${ }^{3}$ It is known that physical exercise promotes upregulation of PPAR- $\delta$, scavenger receptor class $\mathrm{B} 1, \mathrm{ABCA} 1$, and increases lipolysis. ${ }^{51}$

Several PPAR- $\alpha$ agents have superior potency for PPAR- $\alpha$ compared to fibrates. Agonists like CP-778875 or LY518674 increase HDL-C and lower TG levels in lesser doses than fibrates in humans. ${ }^{3,52}$ CP-900691 can both augment HDL-C and drop TG concurrently. ${ }^{3}$

PPAR- $\delta$ agonists are in early trials phase. GW501516 has demonstrated increased HDL-C and decreased TG. ${ }^{3}$ GW0742 did not influence HDL-C production or catabolism but did promote macrophage-to-feces RCT by reducing the expression of Niemann-Pick C1 like 1 protein. ${ }^{53}$

Dual PPAR- $\alpha / \gamma$ agonists (eg, tesaglitazar and muraglitazar) have favorable effects on insulin sensitivity and dyslipidemia. ${ }^{3}$ Both tesaglitazar and muraglitazar reached Phase III trials, but were pulled out due to increased ASCVD events. ${ }^{3}$ Other dual agonists are being tested for safety and efficacy. Another glitazone, aleglitazar, is undergoing Phase II testing..$^{54}$

\section{Endothelial lipase inhibitors}

Endothelial lipase (EL) inhibition may act to diminish ApoA-I catabolism, prompting a rise in ApoA-I and HDL-C.
Overexpression of EL diminishes ApoA-I/HDL-C production from enhanced catabolism in kidneys. Similarly, levels of ApoA-I/HDL-C are increased by deletion in EL genes. ${ }^{7}$ EL gene variation is considered a crucial contributing factor of plasma HDL-C; whether these HDL-C alterations modify atherosclerotic processes remains unclear. ${ }^{7}$ Some studies have shown a clear correlation between coronary artery calcification and plasma level of EL mass. ${ }^{55}$

One study demonstrated augmented plasma HDL-C and reduced atherosclerosis by targeted inactivation of EL. ${ }^{7}$ Novel EL inhibitors made from boronic acid and sulfonylfuran urea are being examined for potency against EL. ${ }^{56}$

In short, carriers of EL variants accompanying higher HDL-C can have decreased risk of CAD, but this correlation is not seen in most EL inhibitor studies. Mendelian randomization showed that variability at CETP and EL genes which raise HDL-C does not appear to reduce the risk of myocardial infarctions. ${ }^{6}$

\section{ApoA-I upregulators}

RVX-208 is a BET bromodomain inhibitor that acts to enhance ApoA-I production and subsequently increase synthesis of HDL particles. RVX-208 administered orally resulted in raised HDL-C and ApoA-I in animals. It also augmented cholesterol efflux from macrophages through pathways mediated by scavenger receptor class B1, ATP-binding cassette transporter family G (ABCG) 1 , and ABCA1. ${ }^{7}$ RVX208 studies in humans revealed similar enhanced efflux of cholesterol with moderate elevation in HDL-C. ${ }^{57}$ RVX-208 showed nonsignificant alterations in ApoA-I and HDL-C when tested in 299 stable CAD patients on statins. ${ }^{58}$

In June 2013, it was reported that that 26 weeks of RVX208 treatment in high-risk ASCVD patients with low HDL-C $(<39 \mathrm{mg} / \mathrm{dL})$ on statins did not meet its primary endpoint of a $-0.6 \%$ change in percent atheroma volume as determined by intravascular ultrasound in an ongoing ASSURE Phase IIb clinical trial. ${ }^{59}$ Later, reports showed it had a statistically significant percent atheroma volume plaque regression of $-1.43 \%(P<0.002)$ in patients on rosuvastatin but had nonsignificant plaque progression of $+0.19 \%$ in people on atorvastatin. $^{59}$

New data stated that RVX-208 lowers inflammatory marker (high-sensitivity C-reactive protein) by $60 \%$ $(P=0.054)$ and incidence of major cardiac events by $63 \%$ $(P=0.023)$ compared to placebo among high-risk patients with elevated levels of this marker. Recently, another Phase II enrollment was completed to examine its effects on glucose metabolism in patients with prediabetes mellitus. ${ }^{59}$ Further 
investigations to see the effects of RVX-208 in atherosclerotic diseases and associated events are ongoing.

\section{LCAT modulators}

LCAT is an enzyme that converts free cholesterol into cholesteryl ester which is then segregated into the core of a lipoprotein particle, allowing maturation of the HDL particles into lipid-rich spherical complexes. ${ }^{40}$ Various approaches exist for modulation of LCAT activity. One approach is using recombinant LCAT protein in familial LCAT deficiency as replacement therapy. However, current data on LCAT mostly comes from animal studies. In one study, rapid increase in HDL-C and reduction in VLDL and lipoprotein-X was observed after infusion of plasma from human LCAT transgenic mice into LCAT-knockout mice. ${ }^{60}$ Fat cells transfected with LCAT transplanted into mouse models also elevated HDL-C. ${ }^{7}$ Human recombinant LCAT infusions tested in rabbits increased fecal cholesterol secretion, elevated HDL-C, and reduced atherosclerotic disease. ${ }^{61}$

Thus far, insufficient information is available on ASCVD outcomes in humans using LCAT modulators.

\section{LXR agonists}

LXRs act as intracellular cholesterol sensors. Presently, there are two isoforms of LXR described: LXR $\alpha$ and LXR $\beta$ (with $80 \%$ homology). LXR $\alpha$ is expressed mostly in adipose tissue, kidney, intestine, and liver. LXR $\beta$ is expressed universally. These receptors sense excess cholesterol and stimulate numerous intracellular mechanisms to safeguard cells from cholesterol burden. Therefore, LXRs are able to promote RCT through extraction of cholesterol from peripheral cells, its circulatory transport to the liver, and subsequent biliary elimination. Also, LXRs suppress intestinal cholesterol uptake. ${ }^{40}$ Synthetic LXR agonists (LXR $\left.\alpha / \beta\right)$ can stimulate the expression of ABCA1 and ABCG1, which are shown to elevate HDL-C and reduce atherosclerosis. ${ }^{62}$

Thus, LXR agonist activation was thought to be a promising target for dyslipidemia treatment. Unfortunately, the development of first generation LXR agents was hindered as they were found to induce lipogenic genes in the liver, resulting in an increase of TG and promotion of hepatic steatosis. ${ }^{40}$ Subsequently, second generation LXR agonists have been developed (eg, LXR-623, GW6340, GW3965, T0901317, ATI-111, AZ876), which exhibit greater potency for $L X R \alpha / \beta$ receptors, yet none have shown affinity for ABCA1 and ABCG1.40,63

The current data on LXR agonists mostly come from animal experimentation, with variable effects on HDL. Agents like LXR-623, T0901317, or AZ876 were shown to increase
HDL-C; however, other agents (GW3965, SB742881, GW6340, ATI-111, and SR9238) either had no effects on HDL-C, decreased HDL-C, or increased LDL-C, VLDL-C, and TG concentrations. ${ }^{3}$ In a human trial, LXR-623 increased the expression of ABCA1 and ABCG1, but the study was terminated early as $>50 \%$ of patients developed central nervous system-related toxicities. ${ }^{64}$

Overall, the net effects of LXR agonists have been discouraging. Many LXR agonists have no effect or insignificant overall effect on lipid profile and HDL-C. Furthermore, their potential to dramatically raise TG levels is a concern.

However, these agents have shown antagonistic effects in atherogenesis and inflammation. For example, some have demonstrated significant effects in decreasing atherosclerotic plaque size (GW3965, T0901317, ATI-111, AZ876), and a few of these showed ability to decrease the number of plaques (AZ876, GW3965), change the composition (T09013117), or even inhibit development of new lesions (GW3965, AZ876). ${ }^{3,7}$ The administration of GW3965 or T0901317 resulted in the reduction of cytokines involved in inflammation and atherogenesis. , $^{3,62,63}$

\section{Synthetic farnesoid $X$ receptor agonists}

Farnesoid X receptors (FXRs) are bile-stimulated nuclear receptors expressed mostly in liver and intestines, which are shown to interact with PPAR. They induce HDL-derived cholesterol excretion from the liver into feces. Preclinical studies suggested antiatherosclerotic effects of FXR activation; therefore, FXR agonists are viewed as a potential treatment target. ${ }^{7}$ Many agents have been produced as possible HDL-C enhancing therapies (FXR-450, 6-ECDCA, PX20606, GW4064). ${ }^{65}$

\section{Gene therapy}

ApoA-I transgenes have produced benefits in atherosclerosis prevention when tested in animal models. A 2013 study reported that an adenovirus-based treatment (Alipogene tiparvovec) in humans with lipoprotein lipase deficiency showed TG reduction in $40 \%$ of subjects; however, HDL-C levels were not reported. ${ }^{66}$

Based on animal experimentation, other new genetic therapies to raise HDL-C by increasing ABCA1/ABCG1 expression could be via application of microRNA (for example; inhibition of miR-33). Overexpression of antisense miR-33 is shown to increase hepatic ABCA1 by $50 \%$, resulting in a $25 \%$ increase in HDL-C. Thus, antagonists of miR-33 appear to be a potential therapeutic target for prevention or treatment of ASCVD. ${ }^{67}$ 


\section{Limitations}

The opinions and conclusions presented in this review represent the authors' understanding of the literature. The goal was to provide a general discussion of the key published findings in HDL pharmacotherapy and to target the question of "current guidelines for HDL in therapies and potential future treatments". It is not an exhaustive summary and may not have captured all relevant studies.

\section{Conclusion}

Low HDL-C is recognized as an independent, major risk factor for ASCVD. Even among patients aggressively treated to reduce LDL-C to satisfactory levels, CVD events still occur, and low HDL-C is a significant risk factor in this group. Plasma HDL-C level may not replicate the functionality of HDL or the effects of a specific HDL-targeted treatment on cardiovascular risk or atherosclerosis. The association between HDL and ASCVD is more complicated, possibly mediated by several HDL functions, for example, RCT and antithrombotic, antioxidant, anti-inflammatory, or antiapoptotic properties.

HDL-targeted pharmacologic strategies have not yet produced convincing enough results to translate into clinical treatment recommendations. Potential new treatments based on HDL physiology remain in early phases of development.

In order to evaluate better association between HDL and ASCVD with potential therapeutic implications, future studies should focus on creating, measuring, and targeting improved biomarkers of various HDL functions instead of HDL-C. Future HDL-targeted pharmacotherapies will need to demonstrate reductions in clinically significant outcomes when added to potent statin therapy.

\section{Disclosure}

Seth S Martin and Steven R Jones are listed as coinventors on a pending patent filed by Johns Hopkins University for a method of LDL-C estimation. The other authors report no conflicts of interest in this work.

\section{References}

1. Boden WE. High-density lipoprotein cholesterol as an independent risk factor in cardiovascular disease: assessing the data from Framingham to the Veterans Affairs High - Density Lipoprotein Intervention Trial. Am J Cardiol. 2000;86(12A):19L22L.

2. Campbell CY, Rivera JJ, Blumenthal RS. Residual risk in statin-treated patients: future therapeutic options. Curr Cardiol Rep. 2007;9(6): 499-505.

3. Mahdy Ali K, Wonnerth A, Huber K, Wojta J. Cardiovascular disease risk reduction by raising HDL cholesterol - current therapies and future opportunities. Br J Pharmacol. 2012;167(6):1177-1194.

4. Assmann G, Gotto AM Jr. HDL cholesterol and protective factors in atherosclerosis. Circulation. 2004;109(23 Suppl 1):III8-III14.
5. Barter P, Gotto AM, LaRosa JC, et al; Treating to New Targets Investigators. HDL cholesterol, very low levels of LDL cholesterol, and cardiovascular events. N Engl J Med. 2007;357(13):1301-1310.

6. Voight BF, Peloso GM, Orho-Melander M, et al. Plasma HDL cholesterol and risk of myocardial infarction: a mendelian randomisation study. Lancet. 2012;380(9841):572-580.

7. Hafiane A, Genest J. HDL, Atherosclerosis, and emerging therapies. Cholesterol. 2013;2013:891403.

8. Lim S, Park YM, Sakuma I, Koh KK. How to control residual cardiovascular risk despite statin treatment: focusing on HDLcholesterol. Int J Cardiol. 2013;166(1):8-14.

9. Hausenloy DJ, Yellon DM. Enhancing cardiovascular disease risk reduction: raising high-density lipoprotein levels. Curr Opin Cardiol. 2009;24(5):473-482.

10. Gao X, Yuan S. High density lipoproteins-based therapies for cardiovascular disease. J Cardiovasc Dis Res. 2010;1(3):99-103.

11. Third report of the expert panel on detection, evaluation, and treatment of high blood cholesterol in adults (Adult Treatment Panel III) [webpage on the Internet]. Bethesda, MD: National Heart, Lung, and Blood Institute, National Institutes of Health; 2002 [updated 2004]. Available from: http://www.nhlbi.nih.gov/guidelines/cholesterol/. Accessed September 29, 2013.

12. Jellinger PS, Smith DA, Mehta AE, et al; AACE Task Force for Management of Dyslipidemia and Prevention of Atherosclerosis. American Association of Clinical Endocrinologists' Guidelines for Management of Dyslipidemia and Prevention of Atherosclerosis: executive summary. Endocr Pract. 2012;18(2):269-293.

13. Reiner Z, Catapano AL, De Backer G, et al; European Association for Cardiovascular Prevention and Rehabilitation; ESC Committee for Practice Guidelines (CPG) 2008-2010 and 2010-2012 Committees. ESC/EAS Guidelines for the management of dyslipidaemias: the Task Force for the management of dyslipidaemias of the European Society of Cardiology (ESC) and the European Atherosclerosis Society (EAS). Eur Heart J. 2011;32(14):1769-1818.

14. Boden WE, Probstfield JL, Anderson T, et al; AIM-HIGH Investigators. Niacin in patients with low HDL cholesterol levels receiving intensive statin therapy. $N$ Engl J Med. 2011;365(24):2255-2267.

15. ClinicalTrials.gov [homepage on the Internet]. Treatment of HDL to reduce the incidence of vascular events HPS2-THRIVE. Bethesda, MD: National Institutes of Health; 2012. Available from: http://clinicaltrials.gov/ct2/show/NCT00461630. Accessed December 6, 2013.

16. Anderson TJ, Grégoire J, Hegele RA, et al. 2012 update of the Canadian Cardiovascular Society guidelines for the diagnosis and treatment of dyslipidemia for the prevention of cardiovascular disease in the adult. Can J Cardiol. 2013;29(2):151-167.

17. Stone NJ, Robinson J, Lichtenstein AH, et al. 2013 ACC/AHA Guideline on the Treatment of Blood Cholesterol to Reduce Atherosclerotic Cardiovascular Risk in Adults: A Report of the American College of Cardiology/American Heart Association Task Force on Practice Guidelines. J Am Coll Cardiol. Epub November 7, 2013.

18. Minder CM, Blaha MJ, Horne A, Michos ED, Kaul S, Blumenthal RS. Evidence-based use of statins for primary prevention of cardiovascular disease. Am J Med. 2012;125(5):440-446.

19. Walldius G, Jungner I. The apoB/apoA-I ratio: a strong, new risk factor for cardiovascular disease and a target for lipid-lowering therapy a review of the evidence. J Intern Med. 2006;259(5):493-519.

20. Moutzouri E, Kei A, Elisaf MS, Milionis HJ. Management of dyslipidemias with fibrates, alone and in combination with statins: role of delayed-release fenofibric acid. Vasc Health Risk Manag. 2010;6: 525-539.

21. Ginsberg HN, Elam MB, Lovato LC, et al; ACCORD Study Group. Effects of combination lipid therapy in type 2 diabetes mellitus. $N$ Engl J Med. 2010;362(17):1563-1574.

22. Bezafibrate Infarction Prevention (BIP) study. Secondary prevention by raising HDL cholesterol and reducing triglycerides in patients with coronary artery disease. Circulation. 2000;102(1):21-27. 
23. Frick MH, Elo O, Haapa K, et al. Helsinki Heart Study: primaryprevention trial with gemfibrozil in middle-aged men with dyslipidemia. Safety of treatment, changes in risk factors, and incidence of coronary heart disease. N Engl J Med. 1987;317(20):1237-1245.

24. Brooks EL, Kuvin JT, Karas RH. Niacin's role in the statin era. Expert Opin Pharmacother. 2010;11(14):2291-2300.

25. Khera AV, Patel PJ, Reilly MP, Rader DJ. The addition of niacin to statin therapy improves high-density lipoprotein cholesterol levels but not metrics of functionality. J Am Coll Cardiol. 2013;62(20):1909-1910.

26. Michos ED, Sibley CT, Baer JT, Blaha MJ, Blumenthal RS. Niacin and statin combination therapy for atherosclerosis regression and prevention of cardiovascular disease events: reconciling the AIM-HIGH (Atherothrombosis Intervention in Metabolic Syndrome With Low HDL/High Triglycerides: Impact on Global Health Outcomes) trial with previous surrogate endpoint trials. J Am Coll Cardiol. 2012;59(23): 2058-2064.

27. Connolly BA, O'Connell DP, LeBlanc DF, et al. ARI-3037MO, a novel niacin analog, significantly improves plasma lipid levels in the hyperlipidemic golden syrian hamster. Circulation. 2011;124:A18285.

28. Blaha MJ, Michos ED. Niacin - a case study for the role of event-driven versus surrogate endpoint trials. Heart. 2013;99(22):1631-1632.

29. Barter PJ, Brewer HB Jr, Chapman MJ, Hennekens CH, Rader DJ, Tall AR. Cholesteryl ester transfer protein: a novel target for raising HDL and inhibiting atherosclerosis. Arterioscler Thromb Vasc Biol. 2003;23(2):160-167.

30. Karalis I, Rensen PC, Jukema JW. Journey through cholesteryl ester transfer protein inhibition: from bench to bedside. Circ Cardiovasc Qual Outcomes. 2013;6(3):360-366.

31. Shah PK, Nilsson J, Kaul S, et al. Effects of recombinant apolipoprotein A-I(Milano) on aortic atherosclerosis in apolipoprotein E-deficient mice. Circulation. 1998;97(8):780-785.

32. Nissen SE, Tsunoda T, Tuzcu EM, et al. Effect of recombinant ApoA-I Milano on coronary atherosclerosis in patients with acute coronary syndromes: a randomized controlled trial. JAMA. 2003;290(17): 2292-2300.

33. Nicholls SJ, Tuzcu EM, Sipahi I, et al. Relationship between atheroma regression and change in lumen size after infusion of apolipoprotein A-I Milano. J Am Coll Cardiol. 2006;47(5):992-997.

34. Ibanez B, Giannarelli C, Cimmino G, et al. Recombinant HDL(Milano) exerts greater anti-inflammatory and plaque stabilizing properties than HDL(wild-type). Atherosclerosis. 2012;220(1):72-77.

35. Tardif JC, Grégoire J, L'Allier PL, et al; Effect of rHDL on AtherosclerosisSafety and Efficacy (ERASE) Investigators. Effects of reconstituted high-density lipoprotein infusions on coronary atherosclerosis: a randomized controlled trial. JAMA. 2007;297(15):1675-1682.

36. Chenevard R, Hürlimann D, Spieker L, et al. Reconstituted HDL in acute coronary syndromes. Cardiovasc Ther. 2012;30(2):e51-e57.

37. ClinicalTrials.gov [homepage on the Internet]. A single ascending dose study examining the safety and pharmacokinetic profile of reconstituted high density lipoprotein (CSL112) administered to patients. Bethesda, MD: National Institutes of Health; 2011 [updated January 8, 2014]. Available from: http://clinicaltrials.gov/show/NCT01499420. Accessed September 28, 2013

38. Product development is innovation [webpage on the Internet] Parsipanny, NJ: The Medicines Company; 2014. Available from: http:/ www.themedicinescompany.com/page/pipeline. Accessed January 1, 2014.

39. Sacks FM, Rudel LL, Conner A, et al. Selective delipidation of plasma HDL enhances reverse cholesterol transport in vivo. J Lipid Res. 2009;50(5):894-907.

40. Degoma EM, Rader DJ. Novel HDL-directed pharmacotherapeutic strategies. Nat Rev Cardiol. 2011;8(5):266-277.

41. Waksman R, Torguson R, Kent KM, et al. A first-in-man, randomized, placebo-controlled study to evaluate the safety and feasibility of autologous delipidated high-density lipoprotein plasma infusions in patients with acute coronary syndrome. $\mathrm{J} \mathrm{Am} \mathrm{Coll} \mathrm{Cardiol.}$ 2010;55(24):2727-2735.
42. Vedhachalam C, Liu L, Nickel M, et al. Influence of ApoA-I structure on the ABCA1-mediated efflux of cellular lipids. J Biol Chem. 2004;279(48):49931-49939.

43. Bloedon LT, Dunbar R, Duffy D, et al. Safety, pharmacokinetics, and pharmacodynamics of oral apoA-I mimetic peptide D-4F in high-risk cardiovascular patients. J Lipid Res. 2008;49(6):1344-1352.

44. Weihrauch D, Xu H, Shi Y, et al. Effects of D-4F on vasodilation, oxidative stress, angiostatin, myocardial inflammation, and angiogenic potential in tight-skin mice. Am J Physiol Heart Circ Physiol. 2007;293(3):H1432-H1441.

45. Navab M, Reddy ST, Anantharamaiah GM, et al. D-4F-mediated reduction in metabolites of arachidonic and linoleic acids in the small intestine is associated with decreased inflammation in low-density lipoprotein receptor-null mice. J Lipid Res. 2012;53(3):437-445.

46. Navab M, Reddy ST, Anantharamaiah GM, et al. Intestine may be a major site of action for the apoA-I mimetic peptide $4 \mathrm{~F}$ whether administered subcutaneously or orally. J Lipid Res. 2011;52(6): $1200-1210$

47. Chattopadhyay A, Navab M, Hough G, et al. A novel approach to oral apoA-I mimetic therapy. J Lipid Res. 2013;54(4):995-1010.

48. Tabet F, Remaley AT, Segaliny AI, et al. The 5A apolipoprotein A-I mimetic peptide displays antiinflammatory and antioxidant properties in vivo and in vitro. Arterioscler Thromb Vasc Biol. 2010;30(2): 246-252.

49. Di Bartolo BA, Nicholls SJ, Bao S, et al. The apolipoprotein A-I mimetic peptide ETC-642 exhibits anti-inflammatory properties that are comparable to high density lipoproteins. Atherosclerosis. 2011;217(2): 395-400.

50. Bielicki JK, Zhang H, Cortez Y, et al. A new HDL mimetic peptide that stimulates cellular cholesterol efflux with high efficiency greatly reduces atherosclerosis in mice. J Lipid Res. 2010;51(6): 1496-1503.

51. Srivastava RA. Evaluation of anti-atherosclerotic activities of PPAR- $\alpha$, PPAR- $\gamma$, and LXR agonists in hyperlipidemic atherosclerosis-susceptible F(1)B hamsters. Atherosclerosis. 2011;214(1):86-93.

52. Nissen SE, Nicholls SJ, Wolski K, et al. Effects of a potent and selective PPAR-alpha agonist in patients with atherogenic dyslipidemia or hypercholesterolemia: two randomized controlled trials. JAMA. 2007;297(12):1362-1373.

53. Berger JP, Akiyama TE, Meinke PT. PPARs: therapeutic targets for metabolic disease. Trends Pharmacol Sci. 2005;26(5):244-251.

54. Henry RR, Lincoff AM, Mudaliar S, Rabbia M, Chognot C, Herz M. Effect of the dual peroxisome proliferator-activated receptor-alpha/ gamma agonist aleglitazar on risk of cardiovascular disease in patients with type 2 diabetes (SYNCHRONY): a phase II, randomised, doseranging study. Lancet. 2009;374(9684):126-135.

55. Tang NP, Wang LS, Yang L, et al. Protective effect of an endothelial lipase gene variant on coronary artery disease in a Chinese population. J Lipid Res. 2008;49(2):369-375.

56. Goodman KB, Bury MJ, Cheung M, et al. Discovery of potent, selective sulfonylfuran urea endothelial lipase inhibitors. Bioorg Med Chem Lett. 2009;19(1):27-30.

57. Bailey D, Jahagirdar R, Gordon A, et al. RVX-208: a small molecule that increases apolipoprotein A-I and high-density lipoprotein cholesterol in vitro and in vivo. J Am Coll Cardiol. 2010;55(23):2580-2589.

58. Nicholls SJ, Gordon A, Johansson J, et al. Efficacy and safety of a novel oral inducer of apolipoprotein a-I synthesis in statin-treated patients with stable coronary artery disease a randomized controlled trial. $J \mathrm{Am}$ Coll Cardiol. 2011;57(9):1111-1119.

59. Resverlogix announces two new findings from the ASSURE Trial Relating to Inflammation and Plaque Vulnerability. [webpage on the Internet]. Calgary, AB: Resverlogix Corporation; 2013. Available from: http://www.resverlogix.com/media/press-release.html?id=494\#. UximyvldUWY. Accessed January 1, 2014.

60. Rousset X, Vaisman B, Auerbach B, et al. Effect of recombinant human lecithin cholesterol acyltransferase infusion on lipoprotein metabolism in mice. J Pharmacol Exp Ther. 2010;335(1):140-148. 
61. Rousset X, Shamburek R, Vaisman B, Amar M, Remaley AT. Lecithin cholesterol acyltransferase: an anti- or pro-atherogenic factor? Curr Atheroscler Rep. 2011;13(3):249-256.

62. Bełtowski J. Liver X receptors (LXR) as therapeutic targets in dyslipidemia. Cardiovasc Ther. 2008;26(4):297-316.

63. Calkin AC, Tontonoz P. Liver X receptor signaling pathways and atherosclerosis. Arterioscler Thromb Vasc Biol. 2010;30(8):1513-1518.

64. Katz A, Udata C, Ott E, et al. Safety, pharmacokinetics, and pharmacodynamics of single doses of LXR-623, a novel liver X-receptor agonist, in healthy participants. J Clin Pharmacol. 2009;49(6):643-649.

65. Mencarelli A, Fiorucci S. FXR an emerging therapeutic target for the treatment of atherosclerosis. J Cell Mol Med. 2010;14(1-2):79-92.

66. Gaudet D, Méthot J, Déry S, et al. Efficacy and long-term safety of alipogene tiparvovec (AAV1-LPLS447X) gene therapy for lipoprotein lipase deficiency: an open-label trial. Gene Ther. 2013;20(4):361-369.

67. Rayner KJ, SuárezY, Dávalos A, et al. MiR-33 contributes to the regulation of cholesterol homeostasis. Science. 2010;328(5985):1570-1573.

68. No authors listed. Clofibrate and niacin in coronary heart disease. JAMA. 1975;231(4): 360-381.

69. Blankenhorn DH, Nessim SA, Johnson RL, Sanmarco ME, Azen SP, Cashin-Hemphill L. Beneficial effects of combined colestipol-niacin therapy on coronary atherosclerosis and coronary venous bypass grafts. JAMA. 1987;257(23):3233-3240.

70. Brown BG, Zhao XQ, Chait A, et al. Simvastatin and niacin, antioxidant vitamins, or the combination for the prevention of coronary disease. N Engl J Med. 2001;345(22):1583-1592.

71. Taylor AJ, Sullenberger LE, Lee HJ, Lee JK, Grace KA. Arterial Biology for the Investigation of the Treatment Effects of Reducing Cholesterol (ARBITER) 2: a double-blind, placebo-controlled study of extendedrelease niacin on atherosclerosis progression in secondary prevention patients treated with statins. Circulation. 2004;110(23):3512-3517.

72. Taylor AJ, Lee HJ, Sullenberger LE. The effect of 24 months of combination statin and extended-release niacin on carotid intima-media thickness: ARBITER 3. Curr Med Res Opin. 2006;22(11):2243-2250.

73. Villines TC, Stanek EJ, Devine PJ, et al. The ARBITER 6-HALTS Trial (Arterial Biology for the Investigation of the Treatment Effects of Reducing Cholesterol 6-HDL and LDL Treatment Strategies in Atherosclerosis): final results and the impact of medication adherence, dose, and treatment duration. J Am Coll Cardiol. 2010;55(24):2721-2726.
74. Barter PJ, Caulfield M, Eriksson M, et al; ILUMINATE Investigators. Effects of torcetrapib in patients at high risk for coronary events. N Engl J Med. 2007;357(21):2109-2122.

75. Bots ML, Visseren FL, Evans GW, et al; RADIANCE 2 Investigators. Torcetrapib and carotid intima-media thickness in mixed dyslipidaemia (RADIANCE 2 study): a randomised, double-blind trial. Lancet. 2007;370(9582):153-160.

76. Nissen SE, Tardif JC, Nicholls SJ, et al; ILLUSTRATE Investigators. Effect of torcetrapib on the progression of coronary atherosclerosis. N Engl J Med. 2007;356(13):1304-1316.

77. Schwartz GG, Olsson AG, Abt M, et al; dal-OUTCOMES Investigators. Effects of dalcetrapib in patients with a recent acute coronary syndrome. N Engl J Med. 2012;367(22):2089-2099.

78. Fayad ZA, Mani V, Woodward M, et al; dal-PLAQUE Investigators. Safety and efficacy of dalcetrapib on atherosclerotic disease using novel non-invasive multimodality imaging (dal-PLAQUE): a randomised clinical trial. Lancet. 2011;378(9802):1547-1559.

79. Cannon CP, Shah S, Dansky HM, et al; Determining the Efficacy and Tolerability Investigators. Safety of anacetrapib in patients with or at high risk for coronary heart disease. $N$ Engl J Med. 2010;363(25):2406-2415.

80. ClinicalTrials.gov [homepage on the Internet]. REVEAL: Randomized EValuation of the effects of anacetrapib through lipid-modification. Bethesda, MD: National Institutes of Health; 2010 [updated November 12, 2013]. Available from: http://clinicaltrials.gov/ct2/show/ NCT01252953. Accessed September 28, 2013.

81. Nicholls SJ, Brewer HB, Kastelein JJ, et al. Effects of the CETP inhibitor evacetrapib administered as monotherapy or in combination with statins on HDL and LDL cholesterol: a randomized controlled trial. JAMA. 2011;306(19):2099-2109.

82. ClinicalTrials.gov [homepage on the Internet]. A study of evacetrapib in high-risk vascular disease (ACCELERATE). Bethesda, MD: National Institutes of Health; 2012 [updated December 19, 2013]. Available from: http://clinicaltrials.gov/show/NCT01687998. Accessed September 29, 2013.

83. Heinecke JW. The not-so-simple HDL story: A new era for quantifying HDL and cardiovascular risk? Nat Med. 2012;18:1346-1347.
Vascular Health and Risk Management

\section{Publish your work in this journal}

Vascular Health and Risk Management is an international, peerreviewed journal of therapeutics and risk management, focusing on concise rapid reporting of clinical studies on the processes involved in the maintenance of vascular health; the monitoring, prevention and treatment of vascular disease and its sequelae; and the involvement of

\section{Dovepress}

metabolic disorders, particularly diabetes. This journal is indexed on PubMed Central and MedLine. The manuscript management system is completely online and includes a very quick and fair peer-review system, which is all easy to use. Visit http://www.dovepress.com/ testimonials.php to read real quotes from published authors. 